\title{
La política exterior del kirchnerismo en la construcción de un realismo discursivo presidencial (2003-2015)
}

The foreign policy of kirchnerism through the construction of a presidential discursive realism (2003-2015)

Juan Pablo Laporte 1

\section{Resumen}

Este trabajo analiza la política exterior del kirchnerismo a través de los discursos presidenciales brindados en la Asamblea Legislativa y en la Asamblea General de las Naciones Unidas cada año, interpretados por los autores que han contribuido al estado de la discusión del período. Estas enunciaciones discursivas, demostraron la intención de diseñar un patrón de inserción internacional orientado al crecimiento interno distributivo. Para ello, se consolidó lo que hemos denominado un realismo discursivo presidencial, entendido como la construcción de poder político desde la argumentación para desarrollar capacidades estatales que posibiliten las transformaciones necesarias para un desarrollo con equidad.

Palabras clave: kirchnerismo, política exterior, discurso, modelo de desarrollo.

\section{Abstract}

This work analyzes the foreign policy of the kirchnerism through the presidential speeches given at the Legislative Assembly and at the General Assembly of the United Nations every year, interpreted for the authors who have contributed to the state of the discussion of the period. These discursive statements demonstrated the intention of designing a pattern of international insertion oriented towards internal distributive growth. For this, it was consolidated what we have called a presidential discursive realism, understood as the construction of political power from argumentation, to develop state capacities that enable the necessary transformations for development with equity.

Keywords: kirchnerism, foreign policy, discourse, development model

Recibido: 30 de octubre de 2020 Aceptado: 4 de diciembre de $2020 \sim$ Publicado: 1 de enero de 2021

1 Doctor en Ciencias Sociales de la Universidad de Buenos Aires. Profesor Titular de Política Exterior Argentina en la Carrera de Ciencia Política de la Universidad de Buenos Aires. Director del Grupo de Investigación de Política Exterior Argentina de la Universidad de Buenos Aires (UBA). Buenos Aires, Argentina. Director de Asuntos Internacionales de la Sociedad Argentina de Análisis Político. Correo electrónico: juanpablolaporte@gmail.com 


\section{Introducción}

En este artículo se analiza la política exterior del gobierno kirchnerista desde los principales trabajos académicos que la abordaron, y su relación con los discursos presidenciales que se enunciaron en la apertura de las sesiones legislativas y en la Asamblea General de las Naciones Unidas.

Al considerar estas dos instancias discursivas, nuestro objetivo principal intenta responder a una pregunta en los estudios de la historia de las relaciones internacionales de la Argentina en el período 2003 a 2015: cómo se enunció el modelo de inserción internacional desde los discursos presidenciales en la apertura de la Asamblea Legislativa y en la Asamblea General de las Naciones Unidas.

Esta elección temática, teórica y metodológica se sustenta en dos motivos:

1. Complementar los estudios históricos de la política exterior argentina a través de la reconstrucción ideológico-discursiva presidencial en las dos principales instancias institucionales de enunciación argumental de las políticas públicas, tanto en el escenario interno como externo.

2. Subsanar una limitación de las investigaciones históricas de la política exterior argentina reciente, en tanto

uno de los principales obstáculos para el desarrollo de la historiografía de las relaciones internacionales de la Argentina es la carencia de fuentes confiables y de documentación accesible debido al lento proceso de desclasificación de los documentos, al estado precario de la organización de los archivos diplomáticos (que en los últimos años se han ido mejorando), y a la escasa accesibilidad de los archivos privados (Rapoport, 2015, p. 32).

Para dicho fin expuesto, en primer lugar, se han recorrido los principales estudios de la política exterior del periodo estudiado desarrollados por historiadores, politólogos e internacionalistas.

En segundo lugar, se ha realizado una interpretación de la totalidad de los discursos que pronunciaron los presidentes Néstor Kirchner y Cristina Fernández de Kirchner tanto en el Congreso de la Nación como en la Asamblea General de las Naciones Unidas.

En tercer lugar, sin perder el recorrido cronológico del período, se han enunciado veintidós ejes temáticos que caracterizan al gobierno estudiado.

Finalmente, se arribaron a conclusiones producto del entrecruzamiento entre la interpretación discursiva, los ejes temáticos y la bibliografía que ha analizado la política exterior de este período histórico. 
Cada uno de los dos espacios institucionales mencionados donde se pronunciaron los discursos es de vital importancia para el entendimiento del tema planteado. En efecto, la enunciación discursiva en la inauguración de sesiones ordinarias en el Congreso por parte del presidente de la Nación marca la orientación de la política internacional en la agenda doméstica. Por su parte, los discursos pronunciados en la Asamblea General de las Naciones Unidas, expresan el horizonte de la política exterior del país frente a la comunidad internacional.

Ambas producciones comparten el estar enmarcadas en las dos principales instituciones democráticas tanto del país como del sistema internacional, y ponen de manifiesto la relación entre la política interna y la política exterior.

En este sentido, el estudio de los discursos en cada espacio de enunciación se enmarca en una relación interdependiente entre el régimen político y la política exterior profundamente estudiada por los historiadores Rapoport y Spiguel (2015).

Como hipótesis de este trabajo planteamos que el gobierno kirchnerista pensó, diseñó y estructuró la política exterior en función de un modelo de desarrollo interno distributivo, alejándose de los patrones tradicionales del formalismo político y diplomático de los gobiernos precedentes.

\section{Creencias y paradigmas para interpretar el mundo}

La política exterior de los gobiernos de Néstor Kirchner y Cristina Fernández de Kirchner ha sido estudiada por un número de publicaciones significativamente mayor a las de los demás gobiernos democráticos.

Muchos de estos trabajos toman fragmentos de los discursos de los presidentes y los cancilleres del período para complementar o fundamentar algún aspecto analizado. En nuestro caso, nos proponemos presentar el "esquema argumentativo"2 completo de la totalidad de los discursos pronunciados para enunciar el patrón de inserción internacional del país. Esta interpretación se hará a partir de la discusión enmarcada en el estado del arte del período que reúne a internacionalistas de las más diversas disciplinas con eje en la mirada de la historia reciente de la política exterior.

El primer concepto que debemos considerar para nuestro estudio es el de estrategia de inserción internacional, entendido como un conjunto de dimensiones, ejes y lineamientos que un gobierno piensa, diseña e implementa para vincularse con el mundo (Lorenzini, 2006, 2007). Esta estrategia está orientada por una visión

\footnotetext{
2 Esquema argumentativo (schéme argumentatif), término utilizado por Chaim Perelman y entendido como aquel que se utiliza para vincular el punto de vista con la premisa utilizada dando un soporte lógico a la argumentación (Garssen, 1995).
} 
paradigmática del sistema internacional y el del país sustentada en un sistema de creencias.

En el caso del kirchnerismo, este sistema cognitivo responde a características estudiadas dentro de los presidencialismos concentrados como un tipo de liderazgo predominante (Herman, 1980) que genera que los actores del esquema de decisión mantengan una de fidelización en torno al actor central.

Este esquema de decisión se constituyó en torno a tres círculos: un círculo íntimo, con el presidente, su esposa y dos ministros de extrema confianza; un círculo próximo en el cual estaba la Cancillería, el Ministerio de Defensa y de Economía; y un círculo influyente que lo conformaban los funcionarios de la Cancillería. Por fuera de este esquema, existía un círculo periférico conformado por las corporaciones empresarias, los partidos políticos, el Congreso y los medios de comunicación aliados (Simonoff, 2012a).

A su vez, existía un sistema de creencias por el cual se reflexionaba y se diseñaba la política exterior, que fueron interpretadas a través de dos textos clásicos de Alexander George (1969, 1991). A partir de este basamento teórico, hemos construido tres niveles interpretativos de este prisma cognitivo: a) las creencias centrales sobre la realidad nacional e internacional; b) las creencias secundarias que las desagregan y c) las creencias operativas que marcan cómo llevar a cabo las anteriores.

En relación con las creencias centrales, los gobiernos kirchneristas concibieron al mundo como un escenario asimétrico de poder y de concentración de la riqueza en desmedro del sur global. Este sistema internacional injusto se basaba en la especulación financiera legitimada en los organismos internacionales y encontraba socios locales que reproducían un patrón de acumulación agroexportador tradicional y funcional a las desigualdades internacionales y sus lógicas internas.

Las creencias secundarias se basaron en un paradigma de raíz latinoamericana, nacional, estado-céntrica y neodesarrollista orientado a un desarrollo interno distributivo. Para el gobierno, la política exterior era considerada como una política pública que intenta que las necesidades internas se traduzcan en posibilidades externas (Lafer, 2002).

Finalmente, el aspecto operacional se logra a partir de una acumulación de capacidades estatales autónomas y un poder discursivo de interpelación popular directa para enfrentar a los poderes fácticos externos e internos.

A partir de este sistema de creencias, se configura lo que hemos denominado un realismo discursivo presidencial: la construcción de un poder político simbólico argumental, centrado en la figura del presidente, que coloca en evidencia las desigualdades sistémicas del mundo y del país, y permite construir una agenda de 
cambios estructurales a partir de la enunciación de esas asimetrías y de las medidas para superarlas.

Este discurso le permite al presidente construir poder desde la argumentación, poniendo en evidencia las tensiones de desigualdad en el escenario nacional e internacional, sumando apoyo de los sectores populares internos y progresistas externos.

Este basamento se observa al comenzar el análisis de la política exterior kirchnerista que tiene un eje central en la "autonomía", tomada como una política pública, pero directamente funcional a un proyecto de desarrollo distributivo "en el marco de una serie de transformaciones económicas y políticas internas" (Miguez, 2016a, p. 127).

Esta política tuvo como punto de apoyo la construcción de poder político desde un discurso presidencial de carácter épico-populista (Casullo, 2014, 2019) y asignando al estado un poder central como articulador de los intereses colectivos. Este poder se sustentó en una coalición sociopolítica progresista, un manejo del Estado para distribuir bienes públicos y la construcción de un bloque regional sudamericano como apoyo para la inserción internacional.

\section{Rupturas con el pasado y características de la 10 nueva política exterior}

En el plano interno, el fenómeno histórico político llamado "kirchnerismo" se inició en un ciclo más extenso y estructural que fue la crisis del modelo de acumulación en el 2001, la consecuente caída de De La Rúa y el interregno del gobierno surgido de esta. En este sentido, "los gobiernos de Néstor y Cristina Kirchner continuaron con el esfuerzo de Eduardo Duhalde por recuperar la credibilidad del país después del colapso económico y apuntaron a reforzar su posición en el espacio subregional" (Llenderrozas, 2012, p. 251).

En el plano político mundial, también es el año 2001 el que da inicio a una nueva configuración de poder en los aspectos de la seguridad internacional y la lucha contra el terrorismo, el que pone en duda la estructura de la estabilidad colectiva, y donde se inicia la llamada "guerra preventiva" por parte de los Estados Unidos. Esta realidad y este concepto "demostró que la anunciada paz mundial de la era posguerra fría no era tal” (Miguez, 2016b, p. 85), como se evidenció en la invasión a Afganistán en 2001 y luego a Irak en 2003, y en un incremento del gasto militar mundial para asegurarla.

En el plano de la economía internacional, en el año 2008 con el colapso de las hipotecas subprime, comienza no solamente una crisis económico-financiera mundial, sino también un cuestionamiento a su funcionamiento sistémico desde los foros 
internacionales. Este replanteo fue un aspecto central del discurso del gobierno de Kirchner.

En el plano de la integración latinoamericana, se fortalecieron y se generaron nuevos espacios institucionales como la Celac, el Mercosur y la Unasur que fueron funcionales a la inserción del país desde esta construcción colectiva de América Latina hacia el mundo.

Profundizando el inicio del ciclo histórico del gobierno, debemos mencionar la dimensión de la crisis de 2001 en dos aspectos. Por una parte, en la dimensión externa, se produjo el debilitamiento del Consenso de Washington que generó las condiciones para la aparición de movimientos políticos de izquierda en América Latina, que serían el sustento regional del gobierno. Por otra parte, en la dimensión interna, esta crisis supuso la aparición de nuevos actores con capacidades importantes de organización y protesta social, quienes son incorporados posteriormente por el kirchnerismo desde el Estado para su proyecto de poder distributivo.

Este nuevo escenario planteó un diseño de política exterior disruptiva con respecto a los años previos de la democracia reciente y específicamente como contracara de la matriz neoliberal menemista en lo paradigmático y discursivo, lo cual derivó en un proceso de ampliación y diversificación en las relaciones internacionales, que luego se cerró en torno a alianzas con actores no tradicionales de la política mundial.

Lo mencionado precedentemente implicó pensar, diseñar e instrumentar una política exterior donde el interés nacional se identificaba con un desarrollo equitativo, una autonomía frente a los poderes hegemónicos y una orientación latinoamericana. Esto se llevó a cabo desde una estructura de decisión vertical, con un discurso llano y directo de fuerte contraste con el pasado reciente, en especial el de la década de los noventa (Busso, 2006).

Para analizar las características del gobierno en materia internacional, recurriremos a dos trabajos de Alejandro Simonoff $(2009,2013)$. En ellos, el autor menciona los siguientes ejes centrales de la política exterior del período: a) la seguridad multilateral como una política de ampliación de los alineamientos automáticos; b) la primacía de la política regional y del Mercosur como plataforma de relacionamiento con el mundo; c) la multiplicación y diversificación de los mercados internacionales; d) la concentración en la salida del default y e) la centralidad del reclamo de las Islas Malvinas.

Al mencionar el tema de la securitización en la agenda global, debemos destacar que en la lucha contra el terrorismo se buscó siempre mantener una posición de apoyo a aquellas intervenciones que tuvieran una legitimación consensual en el seno 
de las Naciones Unidas, la que fue potenciada discursivamente como una diferenciación de intervenciones anteriores.

Asimismo, en lo referente a los vínculos con los países de la región, se explican no tan solo en relación con los intercambios comerciales, sino más profundamente con la construcción de una identidad política con capacidad de negociación en bloque frente al mundo (Rapoport, 2008), marcada fuertemente en los discursos.

Este nuevo fortalecimiento de la dimensión regional dio lugar a la participación en otras instituciones como la Comunidad Sudamericana de Naciones (CSN), la Unión de Naciones Sudamericanas (Unasur) y la Comunidad de Estados Latinoamericanos y Caribeños (Celac). El paradigma latinoamericanista se consolidaba en los hechos y retroalimentaba el discurso.

Pero a pesar de estos espacios constituidos, surgieron iniciativas que fragmentaron esta intención colectiva de América del Sur, como la Alianza para el Pacífico (AP) que formaron México, Colombia, Chile y Perú en el 2012, en un intento por ampliar y consolidar los vínculos con países y regiones más amplios. Tanto Panamá, Costa Rica y Guatemala se encuentran en proceso de adhesión, y Paraguay y Uruguay se constituyeron en observadores.

El problema del endeudamiento modificó el vínculo con los Estados Unidos, que pasó de una posición de mayor colaboración al inicio del gobierno para buscar su apoyo en la negociación internacional a un discurso confrontativo en pos de la construcción de poder interno. Esto generó desencuentros con algunas consecuencias como "la reducción de la cooperación en el área de seguridad, el retiro de estatus aliado extra-OTAN o del Sistema General de Preferencias y el resto de beneficios comerciales" (Simonoff, 2012b, p. 110).

La radicalización del cambio hacia Estados Unidos muestra su mayor tensión en noviembre de 2005, cuando en la Cumbre de la Américas en Mar del Plata, el gobierno argentino colabora y fomenta la contracumbre organizada por Hugo Chávez, lo que dio lugar a una "etapa de tensión y desconfianza de Washington hacia Buenos Aires" (Llenderrozas, 2012, p. 253).

A estos ejes planteados que caracterizaron el gobierno, se le suman otros y se hacen algunas precisiones con los aportes de Torres (2010). Este autor plantea que la inserción internacional del gobierno de Kirchner se definió principalmente por a) una concepción amplia del entorno regional y del Mercosur; b) la búsqueda de la moderación en la relación con EE.UU.; c) la promoción internacional de la política de Derechos Humanos y d) la política adoptada frente al problema del endeudamiento externo (p. 3).

Este autor plantea claramente la doble dimensión empírico-discursiva del gobierno que venimos mencionando, en el sentido de que el discurso "se revistió de 
una retórica de confrontación compuesta de dialécticas y reivindicaciones” que intentó todo el tiempo "sumar adeptos y plantear antinomias" (p. 5), pero muchas veces en los hechos se continuaron con compromisos históricos y tradicionales.

Este modelo argumental se diferencia de otros tipos de discursos presidenciales de tipo formalista que abordan temas de carácter protocolar o institucional, y resguarda los temas de fondo para negociaciones fuera de la argumentación pública, tanto interna como externa.

Otra característica discursiva del kirchnerismo fue exponer a la opinión pública los intereses inobservables y no visibilizados de la estructuración de poder real, tanto en el plano nacional como internacional. En este sentido, se buscó delimitar y señalar a los actores tradicionales y hegemónicos de la política, la economía y los medios de comunicación, y crear una lógica de confrontación para construir poder para enfrentarlos.

En el plano externo, las características se resumen en "una diversificación de las relaciones internacionales y la reorientación de las alianzas estratégicas en algunos de los países del Cono Sur" que funcionan como "plataforma para las políticas de autonomía o para el distanciamiento respecto de la potencia del Norte (Miguez, 2016b, p. 92).

A su vez, para Russell y Tokatlian, es la oposición limitada a los Estados Unidos, la cuestión Malvinas y la prioridad latinoamericana lo que caracterizó el período del gobierno kirchnerista (Russell y Tokatlian, 2015).

Finalmente, podemos plantear que la política internacional del gobierno kirchnerista se enmarca en el linaje de los gobiernos peronistas, en el sentido de plantear una "doctrina de poder" que adecúa los contenidos ideológicos a los momentos históricos particulares orientados al desarrollo con equidad. Esto dificulta su caracterización dentro de los paradigmas tradicionales de la política exterior y motiva a crear nuevas interpretaciones.

\section{Una política que mira hacia el interior desde la autonomía}

Llegados a este punto, sostenemos que una primera característica del gobierno que unifica a varios autores, y a la cual adherimos, es que la política exterior argentina durante estos años mostró un cambio sustancial y estructural de paradigma en relación con los gobiernos precedentes.

El núcleo de este cambio estuvo basado en la búsqueda de una autonomía relativa con respecto a los actores tradicionales que se fortalecieron en los años noventa y principio de los dos mil: los Estados Unidos y los organismos internacionales de financiamiento, especialmente el Fondo Monetario Internacional. 
A su vez, esto tenía como objetivo en el plano de la política exterior la búsqueda de la ampliación de los márgenes de decisión, alejándose del modelo de dependencia a través de una prioridad regional para alcanzar el desendeudamiento y la ampliación de nuestro comercio exterior (Simonoff, 2014, p. 441).

Otra característica compartida por la mayoría de los historiadores e internacionalistas, y que es central en nuestro fundamento, es que la política internacional del kirchnerismo fue utilizada como "variable de ajuste en un denodado esfuerzo por acumular capital político interno” (De La Balze, 2010, p. 123).

Esta característica es compartida por Roberto Miranda (citado por Simonoff, 2008), quien expresa que el gobierno de Kirchner "se destacó por el predominio de la agenda doméstica sobre la estrategia de vinculación con el mundo” (p. 11), marcando una lógica de construcción de la política exterior supeditada al dominio de lo interno.

Por su parte, Francisco Corigliano (2011) sostiene que esta es una típica "política exterior peronista", pero adaptada al siglo XXI. Si bien es discutible la comparación por no ajustarse directamente al patrón del peronismo que fue la Tercera Posición en el marco de la Guerra Fría, tiene algunos rasgos que permiten hacer comparaciones histórico-contextuales: a) una conducción vertical del poder concentrada en el presidente; b) una marginación del Congreso en la toma de decisiones y c) el diseño de una diplomacia paralela por fuera de los canales oficiales y con actores informales.

En síntesis, se construye un esquema de decisión con una marcada verticalidad política sobre la profesionalidad diplomática que hizo primar el poder de la institución presidencial sobre la Cancillería.

En este sentido, consideramos que, si bien no se llega al extremo de una "renuencia en general sobre los temas de política exterior, a excepción de aquellas cuestiones de agenda inmediata vinculadas a necesidades internas" (Llenderrozas, 2012, p. 256), sí observamos una relación de primacía relativa de los intereses internos por sobre la agenda global.

Una primera conclusión, que luego se confirma en los discursos, es que el patrón de inserción internacional del gobierno kirchnerista se caracteriza por una política internacional contrapuesta al internacionalismo neoliberal, con una retórica de corte levemente nacionalista, neodesarrollista e industrialista, de clivaje latinoamericano y de prioridad del modelo de desarrollo interno.

\section{Las relaciones bilaterales en clave K}

Las relaciones con el mundo se inscribieron en lo que hemos llamado un multilateralismo periférico: el reconocimiento de un mundo jerárquico y asimétrico, ubicando a la Argentina en el sur global y construyendo el mayor número de 
relaciones posibles en los temas beneficiosos para el país, orientados al desarrollo interno y distributivo para superar esas desigualdades.

Con los Estados Unidos, en el inicio del gobierno, el vínculo estuvo centrado en la necesidad de contar con su apoyo para la renegociación de la deuda (Nemiña, 2011). A lo largo del período, esta relación fue formal con una fuerte retórica antagónica a medida que se alejaba de aquella necesidad. No obstante, en la práctica se mantuvieron muchos temas de cooperación bilateral: terrorismo, narcotráfico, derechos humanos y la no proliferación de armas nucleares (De La Balze, 2010, p. 125).

Una vez solucionado el tema de la negociación de la deuda -primero con los tenedores privados en 2005 y luego con el acuerdo con el FMI y la cancelación de la deuda de casi 10.000 millones de dólares en 2006-, se inició un discurso más agresivo y de corte antiimperialista, enfocado a satisfacer ideológicamente a los actores de la coalición interna.

Pero esta ambigüedad entre lo argumentativo y lo pragmático, tuvo que ver con un "ajuste" de la relación más que con una reestructuración sistémica de fondo (Busso, 2006) orientada a construir un discurso distante con la potencia hegemónica.

Esta tensión manifiesta se expresó en el proyecto de potenciación de integración del Mercosur que fomentaba Argentina y que se contraponía con el ALCA liderado por Estados Unidos, y que tuvo su máxima expresión en la Cumbre de Mar del Plata en 2005, que deterioró las relaciones formales entre los dos países y de los presidentes en su vínculo personal (Russell, 2008).

A pesar de estos desencuentros, los Estados Unidos apoyaron a la Argentina en la negociación frente al Club de París sin la participación del FMI y en el rechazo al embargo de las reservas internacionales del país en el juicio en la ciudad de Nueva York con los bonistas que quedaron fueran del canje de la deuda.

Finalmente fueron dos acciones que dieron por finalizado el "alineamiento automático" con los Estados Unidos: la negación al envío de tropas a Irak sin la aprobación de las Naciones Unidas y el rechazo junto a Brasil del envío de tropas al Líbano (Miguez, 2016b, p. 99).

Frente a estas negativas, hubo una cooperación en materia de Operaciones de Paz en Chipre, Haití, Bosnia, Medio Oriente, Guatemala, Yugoslavia, Sahara Oriental, Timor Oriental, Bélgica y Kosovo. A su vez, se les dio continuidad a los ejercicios militares conjuntos, pero tuvieron la particularidad de que "debieron ser aprobadas por el Congreso y no se garantizó inmunidad para las tropas" (Miguez, 2016b, p. 101).

En el caso de la relación con China, con la visita del presidente $\mathrm{Hu}$ Jintao como retribución al viaje de Kirchner, se firmaron una cantidad significativa de acuerdos 
(Acuerdo Marco de Cooperación Tecnológica para el Uso Pacífico del Espacio Ultraterrestre, el Memorándum de Entendimiento sobre el Programa de Ejecución de Viajes a Argentina de Grupos Turistas Chinos, el Memorándum de Entendimiento para la Cooperación en Proyectos de Ferrocarril y el Memorándum de Entendimiento para el Reforzamiento del Intercambio y la Cooperación en la Educación) y se anunció un volumen de inversiones de 20.000 millones de dólares que luego fue desmentido por el propio gobierno chino (Llenderrozas, 2012, p. 253).

De este país se recibieron inversiones aplicadas a los ferrocarriles, el petróleo y el hierro que se intercambiaron especialmente por soja para el amplio mercado poblacional chino (Miguez, 2016b, p.93) y aumentaron el comercio bilateral con momentos de superávit a favor de la Argentina (Wise \& Quiliconi, 2007).

En este sentido, existieron entre ambos países una serie de coincidencias que solidificaron las relaciones bilaterales:

(...) los acuerdos básicos de experiencias histórica vinculadas al colonialismo; el reconocimiento de los principios de no intervención e integridad territorial; la necesidad de introducir reformas al sistema de Naciones Unidas y al Consejo de Seguridad en defensa del equilibrio geográfico y la representación de distintas culturas; las propuestas de cambios a la arquitectura financiera internacional -modificación de la cuota- voto en el Fondo Monetario Internacional y el Banco Mundial (Miguez, 2016a, p. 132).

El aspecto negativo de este vínculo fue el déficit estructural comercial proyectado, dado el poco o nulo valor agregado de las exportaciones argentinas hacía ese país (Bolinga, 2015).

En este vínculo bilateral, se advirtió una tendencia relacional hacia una reprimarización y hacia un nuevo extractivismo (Miguez, 2016a, p. 133) como modelo de exportación de materias primas a cambio de productos manufacturados y de financiamiento focalizado en los intereses de China en esta relación asimétrica.

Otro actor de peso en la reconfiguración del balance de poder del kirchnerismo fue Rusia. Con este país se alcanzaron acuerdos en áreas como el gas, el petróleo, la energía nuclear y la hidroeléctrica. A su vez, Rusia apoyó a la Argentina en la causa Malvinas y en la renegociación con los tenedores de bonos de deuda.

Como en el caso de China, también hubo una serie de reciprocidades como el acompañamiento a la negociación de la deuda internacional y el reclamo sobre las Islas Malvinas. Por su parte, la Argentina votó en el seno de la ONU con la abstención a condenar la anexión de Crimea. 
En relación con los países europeos, la política exterior estuvo enmarcada al inicio por el acuerdo entre la Unión Europea y el Mercosur, las disputas en torno al Centro Internacional de Arreglo de Diferencias Relativas a Inversiones (CIADI), perteneciente al Banco Mundial, y la relación con aquellos países que tenían tenedores privados de deuda argentina, como Alemania e Italia, que se vieron en la obligación de defender esos intereses. A estos se sumaban los países con inversiones consolidadas desde los años 90, como era el caso de España y Francia.

El telón de fondo de las relaciones tanto como bloque como con cada país europeo en particular fue la crítica a la falta de seguridad jurídica, referida a la pesificación, la renegociación de las tarifas y las nacionalizaciones (Correo Argentino, Aguas Argentinas, Grupo Suez, Thales Spectrum, Tandanor, Aerolíneas Argentinas y Austral, YPF, Fondos de Jubilaciones y Pensiones, etc.).

$\mathrm{Al}$ analizar el vínculo con los países de la región, debemos considerar el cambio de paradigma interpretativo que giró de un comercialismo como regionalismo abierto de carácter "cepalino", pero en armonía con los procesos de liberalización de los años noventa, a un regionalismo posliberal (Sanahuja 2009) y poshegemónico (Riggirozzi y Tussie, 2012) que colocaba en el centro del espacio latinoamericano a la política y la identidad cultural.

Este cambio generó procesos de integración como el fortalecimiento del Mercosur, la Unión de Naciones Suramericanas (Unasur), la Comunidad de Estados Latinoamericanos y Caribeños (Celac) y la Alianza Bolivariana para los Pueblos de Nuestra América.

En relación con el Mercosur especialmente, este espacio se constituyó como un "lugar privilegiado" para las relaciones internacionales de la Argentina (Zelicovich, 2011, p. 181), y proyectar desde allí un nuevo diseño de patrón de inserción internacional.

En este sentido, este aspecto de la política regional se estableció según Simonoff (2010) como "uno de los contrapuntos con el discurso de los noventa que sobreestimaba a los Estados Unidos como eje de nuestro relacionamiento externo" (p. 408).

Finalmente, para Zelicovich (2011) el Mercosur funcionó como un camino para el desarrollo de la viabilidad de la inserción internacional, una herramienta tanto para expandirse en la región y las negociaciones con terceros, y para la realización del modelo de desarrollo interno.

En relación con Brasil, se esperaba de este país un apoyo en la negociación con el FMI, pero que no se concretó. Argentina, por su parte, no lo acompañó para lograr un asiento en el Consejo de Seguridad de la ONU, y fue notoria la ausencia de 
Kirchner en la Cumbre Sudamericana de Cuzco en diciembre de 2014, donde se creó la Comunidad Sudamericana de Naciones (Llenderrozas, 2012, p. 254).

No obstante lo mencionado, en el nuevo tablero regional la relación con este país fue central en el intercambio comercial, la estructuración industrial recíproca y la recepción de inversiones (Miranda, 2009). Esto potenció la integración productiva en la región, pero generando una "interdependencia asimétrica” entre ambos países (Russell y Tokatlian, 2011, P. 15).

Estas asimetrías se potenciaron por la internacionalización de las empresas y capitales brasileños, así como por su banca de desarrollo. Ambas sirvieron como elementos de la política exterior de ese país, y fue América Latina su principal destinatario, incluyendo la Argentina (Actis, 2015).

Con Uruguay, la afinidad esperada con el gobierno de Tabaré Vázquez se opacó rápidamente con el conflicto de las pasteras. Esto generó sentimientos recíprocos de enemistad entre los pueblos de las fronteras vecinas, y algunos niveles de la Cancillería manejaron el conflicto con cierta falta de diplomacia profesional, sumado a declaraciones mediáticas que no contribuyeron.

Con Chile, la relación se inició al constituirse en 2006 la Fuerza de Paz Conjunta y Combinada Cruz del Sur, en el marco de las Naciones Unidas para operaciones de paz. Esto se completó con la visita de Cristina Fernández a este país para celebrar el $30^{\circ}$ aniversario de la mediación del Papa Juan Pablo II.

Este vínculo se enmarcó en el diálogo dentro de la frontera común que fue aumentando una vez superados los conflictos limítrofes y establecidas las "Medidas de Confianza Mutua”. Esta relación se consolidó durante el periodo estudiado, especialmente con el tratado de Maipú de 2009.

Este tratado fue el reconocimiento a los Comités de Integración y a las actividades de las provincias de ambos lados de la cordillera y a la Comisión Parlamentaria Conjunta (Colacrai, 2016, pp. 90-91). A su vez las provincias, constituyeron Comisiones Mixtas-Binacionales que complementaron el proceso federal de integración.

En relación con la cooperación en torno a la Antártida, se refuerza especialmente en la Declaración Presidencial conjunta del 16 de marzo de 2012 entre Cristina Fernández de Kirchner y Sebastián Piñera Echenique (Colacrai, 2016, p. 96).

Este vínculo tuvo sus altibajos al no poder cumplir con la provisión de gas por el aumento de la demanda en nuestro país (Colacrai, 2010), a pesar de la buena relación incipiente con el presidente Lagos y las coincidencias ideológicas aparentes. Esto se compensó con la posibilidad de operar otorgada a la línea aérea LAN, con el acuerdo minero para la instalación de la empresa Barrick Gold en el proyecto Pascua Lama y con los mecanismos de interconsulta bilateral (De la Balze, 2010, p. 133). 
Finalmente, la relación se vio perturbada por las restricciones impuestas a la compañía LAN para operar normalmente en el aeropuerto Jorge Newbery, el caso de Sergio Aplabaza y ciertas limitaciones al comercio bilateral en sectores como textiles, plástico, insumos agroindustriales y mineros, relacionados a los costos aduaneros por la demora en el permiso de ingreso al país.

Con Venezuela, se estructuró una relación de comercialización energética y obtención de financiamiento a tasas "superiores a las que se hubieran obtenido de los organismos financieros internacionales" (Llenderrozas 2012, p. 255), que fue altamente criticada por la oposición, y una variedad de analista económicos y políticos.

Formalmente, este vínculo se inició con la reunión de Ministros de Relaciones Exteriores en julio de 2003 en Buenos Aires, que finalizó con una Declaración de Cancilleres, quienes se comprometieron al desarrollo de proyectos en las áreas de energía, agricultura y alimentos, aeronáutica y satelital, medicina de alta complejidad, metalúrgica y metalmecánica, turismo, medio ambiente e infraestructura.

Esta relación tuvo dos beneficios y una complicación (De La Balze, 2010, p. 131). Por un lado, Venezuela es un actor de peso mundial en el negocio del crudo, lo que provocó que la sociedad con este país fortaleciera todo esquema de negociación general. Asimismo, es un importador de bienes y servicios de la Argentina. Pero por otro lado, el régimen político del chavismo generó un distanciamiento con otros países y organismos internacionales que se aceleró y profundizó en la medida que el régimen se radicalizaba hacía un populismo con rasgos militaristas.

Con el cambio de gobierno a Cristina Fernández de Kirchner, si bien se observa un leve giro en la política exterior durante su administración que fue la base de la campaña electoral (una agenda de mayor institucionalidad y una diferente inserción en el mundo), en los hechos, el realismo discursivo presidencial de confrontación se acentuó, aunque ciertamente mejoró su calidad argumentativa.

A su vez, a la priorización del Mercosur y a Latinoamérica, se le incorporan relacionamientos de tipo bilaterales y de cooperación internacional como elementos de "ajustes" de la política regional (Zelicovich, 2011, p.188). A esto se les suma el reforzamiento del vínculo con Venezuela y la ampliación a organismos regionales como la Unasur.

En cuanto a la estructura del gobierno de Cristina Kirchner, para Simonoff, ha sido de consolidación de la anterior administración, en tanto se fortaleció la "investidura presidencial, no así el resto del andamiaje institucional (Parlamento, Partidos Políticos, etc.), con una estructura de círculos concéntricos donde el Canciller está desplazado hacia la periferia del proceso decisorio" (Simonoff, 2013, p. 6). 
Como corolario de ambos gobiernos, sostenemos que "la estrategia de inserción internacional no puede comprenderse en forma separada del contradictorio devenir del proyecto económico y político interno" (Miguez, 2016a, p. 140) y que la concentración de poder político hacía el final del periodo llevó a extremar la lógica confrontativa en el plano discursivo, tanto en lo interno como en lo internacional.

Para interpretar el sentido de esta argumentación, es necesario sumergirse en los discursos que se enunciaron con la intención de fundamentar la relación entre el modelo de desarrollo interno y el diseño del patrón internacional para llevarlo a cabo.

\section{La política exterior en el período kirchnerista desde sus discursos}

En este apartado, se expondrán los discursos presidenciales enunciados en la Asamblea Legislativa y la Asamblea General de la Organización de las Naciones Unidas, interpretados a partir del estado de la discusión del periodo histórico estudiado.

Como mencionamos previamente, se interpretará el "esquema argumentativo" completo de los discursos de manera cronológica en ambos espacios institucionales para construir el sentido argumental general del período.

A lo largo de la exposición, se irán señalando los ejes centrales de la política exterior del gobierno y su relación con el modelo de desarrollo interno.

Lo que demuestran estas fuentes en los dos ámbitos institucionales es la construcción discursiva de un modelo de desarrollo estatocéntrico distributivo. Este desarrollo se articula con una política exterior de proyección latinoamericana que se contrapone a los periodos precedentes que se ubicaban en una alineación a los centros hegemónicos de poder internacional.

\subsection{El Gobierno de Néstor Kirchner}

\subsubsection{Un discurso fundacional con intenciones de un cambio disruptivo}

El período se inicia con una argumentación fundacional como el primer eje de la política exterior al asumir la presidencia Néstor Kirchner ante la Asamblea Legislativa el 25 de mayo de 2003. En este discurso se destaca "que el conjunto de la sociedad argentina sepa hacia dónde vamos, y cada uno pueda a su vez aportar su colaboración para la obtención de los fines que los argentinos deberemos imponernos por encima de cualquier divisa partidaria”. Aparece desde el inicio, el objetivo de ampliar su apoyo social para superar una legitimidad de origen débil, sustentada en el veintidós por ciento de los votos obtenidos. Para esto, era necesario comenzar a crear una coalición nacional con un carácter multipartidario y multisectorial, con capacidad 
de enfrentar a los poderes hegemónicos de manera electoral, discursiva y con nuevas capacidades estatales.

Y en su intento de marcar este hito fundante, expresa que:

"el 27 de abril las ciudadanas y los ciudadanos de nuestra Patria, en ejercicio de la soberanía popular, se decidieron por el avance decidido hacia lo nuevo. Dar vuelta una página de la historia no ha sido mérito de uno o varios dirigentes. Ha sido, ante todo, una decisión consciente y colectiva de la ciudadanía argentina. El pueblo ha marcado una fuerte opción por el futuro y el cambio".

La palabra "cambio" es reforzada en este inicio en tanto "en esas condiciones debe quedarnos absolutamente claro que en la República Argentina, para poder tener futuro y no repetir nuestro pasado, necesitamos enfrentar con plenitud el desafío del cambio" y que este debía venir "por mandato popular, por comprensión histórica y por decisión política”. Concretamente "cambio es el nombre del futuro".

Y este cambio incluía el "cambiar los paradigmas desde los que se analiza el éxito o el fracaso de una dirigencia y de un país".

\subsubsection{La ruptura con el pasado}

Esta primera parte del discurso marca el segundo eje constitutivo de la política exterior: la ruptura estructural con un modelo tradicional de política económica perimido y causante de la crisis. La sociedad y la dirigencia política debían cambiar sus sistemas de creencias porque en:

"los ochenta se puso el acento en el mantenimiento de las reglas de la democracia y los objetivos planteados no iban más allá del aseguramiento de la subordinación real de las fuerzas armadas al poder político. Posteriormente, "en la década de los noventa, la exigencia sumó la necesidad de la obtención de avances en materia económica, en particular en materia de control de la inflación”.

Seguidamente se inicia la matriz argumentativa fundamental del periodo que fue un fuerte cuestionamiento a esos años noventa: "La medida del éxito de esa política le daban las ganancias de los grupos más concentrados de la economía, la ausencia de corridas bursátiles y la magnitud de las inversiones especulativas”. Esto ha dado como resultado "la consolidación de la pobreza y la condena a millones de argentinos a la exclusión social, la fragmentación nacional y el enorme e interminable endeudamiento externo”.

\subsubsection{Una política estado céntrica}


Un tercer eje constitutivo de la política internacional se caracteriza por un rol del estado que asume una centralidad exclusiva en "promover políticas activas que permitan el desarrollo y el crecimiento económico del país, la generación de nuevos puestos de trabajo y una mejor y más justa distribución del ingreso", en tanto "el Estado cobra en eso un papel principal, es que la presencia o la ausencia del Estado constituye toda una actitud política”.

Y para esto se apoya en "recuperar los valores de la solidaridad y la justicia social que nos permitan cambiar nuestra realidad actual para avanzar hacia la construcción de una sociedad más equilibrada, más madura y más justa" e insiste en que "el mercado organiza económicamente pero no articula socialmente", por eso "debemos hacer que el Estado ponga igualdad allí donde el mercado excluye y abandona”.

Y por si quedaban dudas sobre la estatalidad, afirma que:

"es el Estado el que debe actuar como el gran reparador de las desigualdades sociales en un trabajo permanente de inclusión y creando oportunidades a partir del fortalecimiento de la posibilidad de acceso a la educación, la salud, y la vivienda, promoviendo el progreso social basado en el esfuerzo y el trabajo de cada uno".

A su vez "es el Estado el que debe viabilizar los derechos constitucionales, protegiendo a los sectores más vulnerables de la sociedad, es decir, los trabajadores, los jubilados, los pensionados, los usuarios y los consumidores".

\subsubsection{La región para ampliar el regreso al mundo}

El cuarto eje de la política internacional es el de regionalismo, en tanto el "país debe estar abierto al mundo, pero abierto al mundo de una manera realista, dispuesto a competir en el marco de políticas de preferencia regional -fundamentalmente a través del Mercosur-, y de políticas cambiarias flexibles acorde a nuestras productividades relativas y a las circunstancias del contexto internacional". Y la relación de esta política con la economía tendrá lugar con "una demanda creciente que aliente las inversiones, tanto para atender el mercado interno como a las exportaciones".

\subsubsection{La pesada herencia de la deuda}

Aparece el cuarto eje de la política exterior, que es la resolución de la deuda pública como uno de los causantes estructurales de los impedimentos al desarrollo de los países periféricos en general y de Argentina en particular. En este tema crónico de la Argentina,

"no se puede recurrir al ajuste ni incrementar el endeudamiento. No se puede volver a pagar deuda a costa del 
hambre y la exclusión de los argentinos generando más pobreza y aumentando la conflictividad social". Para esto "la inviabilidad de ese viejo modelo puede ser advertida hasta por los propios acreedores, que tienen que entender que sólo podrán cobrar si a la Argentina le va bien".

Esta "deuda soberana en actual situación de default" será encarada "apuntando a tres objetivos: la reducción de los montos de deuda, la reducción de las tasas de interés y la ampliación de los plazos de madurez y vencimiento de los bonos". El mensaje era claro: "Creciendo nuestra economía crecerá nuestra capacidad de pago".

\subsubsection{Construir poder desde el derecho internacional}

Seguidamente, aparece el quinto eje que es el "fortalecimiento del derecho internacional, el respeto a nuestras convicciones, la historia y las prioridades nacionales". Por cierto, este derecho internacional es entendido como la democratización e igualación de los países frente a las estructuras de veto como el Consejo de Seguridad de las Naciones Unidas.

\subsubsection{Multilateralismo periférico}

El séptimo eje enunciativo es estar a favor de "la política mundial de la multilateralidad", y para esto "no debe esperarse de nosotros alineamientos automáticos sino relaciones serias, maduras y racionales que respeten las dignidades que los países tienen”.

Pero este multilateralismo tiene como "prioridad en política exterior" la "construcción de una América Latina políticamente estable, próspera y unida con base en los ideales de democracia y justicia social”.

\subsubsection{El reclamo histórico sobre Malvinas}

Como octavo eje central y pilar de esta política exterior, está el sostenido “reclamo de soberanía sobre las Islas Malvinas" que se repetirá en todos los discursos, tanto en la Apertura de Sesiones en el Congreso de la Nación como en la Naciones Unidas, y se irá reforzando como resonancia para instalar el tema del "colonialismo del siglo XXI".

\subsubsection{El rol de la potencia hegemónica}

Un noveno eje discursivo se enmarca en construir una "relación seria, amplia y madura con los Estados Unidos de América" que "es lo que debe esperarse de nosotros". Se plantea claramente una relación con la potencia hegemónica razonable, equilibrada y equidistante de los demás centros de poder mundial. 


\subsubsection{Las misiones de paz en el marco de la ONU}

El décimo eje del gobierno se sustenta en fomentar "una participación en pro de la paz y la obtención de consensos en ámbitos como la Organización de las Naciones Unidas". Estas misiones de paz en el marco de la ONU se transforman en una política activa del gobierno.

\subsubsection{La securitización y el terrorismo}

Asimismo, dentro de este ámbito, se enuncia el décimo primer eje que es el compromiso con la "lucha contra el terrorismo internacional" que se transforma en una manera de colaborar indirectamente con los Estados Unidos desde una causa justificable en las "tan profundas y horribles huellas" que "ha dejado en la memoria del pueblo argentino", haciendo referencia al atentado a la Embajada de Israel y la AMIA.

\subsubsection{Cambio en el modelo agroexportador tradicional}

En el plano de las relaciones económicas internacionales, se enuncia el décimo segundo eje de la política internacional que se relaciona con la reconfiguración de "la inserción comercial de la Argentina". El nuevo esquema debe basarse en "profundizar la estrategia de apertura de mercados, incrementar sustancialmente nuestro intercambio con el resto del mundo", pero sobre todo "diversificar exportaciones hacia bienes con mayor valor agregado" y "multiplicar el número de exportadores de modo que los beneficios del comercio exterior se derramen sobre todas las ramas productivas".

Esta argumentación sobre los principios y pilares de la política exterior son ampliados en el marco de la $58^{\circ}$ Asamblea General de las Naciones Unidas del 25 de septiembre de 2003. En este sentido, se insiste en "reafirmar la multilateralidad" que "no puede agotarse en un mero ejercicio discursivo" y debe armonizarse con otro de los ejes mencionados como la "seguridad", ya que son "elementos inseparables".

\subsubsection{La denuncia de un mundo desigual}

Luego, se introduce como el décimo tercer eje, el entender que "el mundo transita tiempos de cambio en el marco de la globalización, que crea oportunidades y riesgos sin precedentes", al entender que "el más grande riesgo es el ensanchamiento de la brecha existente entre ricos y pobres, países centrales y países periféricos”, lo que genera "una realidad lacerante en términos de pobreza y exclusión social sin precedentes. Nuestra prioridad debe ser lograr que la globalización opere para todos y no para unos pocos".

Dos de los principios anunciados previamente se refuerzan en esta Asamblea Legislativa. Primero, "la integración económica" y "la multilateralidad política" que 
serán la clave para que "el mundo sea un lugar más seguro". Segundo, el problema de "la existencia de una aplastante y gigantesca deuda, tanto con organismos multilaterales de crédito como con acreedores privados", lo que aparece como una las causas de la crisis heredada.

\subsubsection{La amplificación de los derechos humanos en el plano internacional}

A su vez, se expresa en este foro internacional "la defensa de los derechos humanos" como el décimo cuarto eje de la política exterior, que "ocupa un lugar central en la nueva agenda de la República Argentina” y se refuerza reiterativamente el reclamo sobre "la disputa de soberanía que mantenemos por las islas Malvinas, Georgias del Sur y Sandwich del Sur y los espacios marinos circundantes”.

El segundo discurso del presidente Néstor Kirchner en la Asamblea Legislativa del $1^{\circ}$ de marzo de 2004 refuerza el tema de la deuda externa, puesto que "el más riguroso examen histórico demuestra que desde los inicios de nuestra historia el endeudamiento fue constante y los pagos resultaron problemáticos". Ante esto, el gobierno exhorta a que no "se comprometerá nada que no resulte posible cumplir".

\subsubsection{Honrar los compromisos internacionales, pero orientados a un modelo de desarrollo basado en el crecimiento sustentable}

Como décimo quinto eje internacional, en esta Asamblea se enuncia que su política se basa en un modelo de "sustentabilidad interna, crecimiento con equidad, cumplimiento con los organismos multilaterales en las condiciones acordadas" y un “crecimiento sustentable en el largo plazo". Pero se deja en claro que no se pagará la deuda "a costa del hambre y la exclusión de millones de argentinos". Para esto se requiere "corregir los problemas de inserción de países en desarrollo en la economía internacional" como "presupuesto básico para generar consensos y estabilidad".

Y a modo de resumen del patrón de inserción internacional propuesto, se expresa que el país se integrará al mundo "con sustento en relaciones equilibradas, soberanas e independientes tendientes al fortalecimiento de la paz y la seguridad asentadas en el derecho internacional, el multilateralismo, el respeto a la autodeterminación de los pueblos y la defensa de los derechos humanos".

Esta inserción, sólo será posible a través de un "fortalecimiento del consumo interno" y "de una apertura simétrica de los mercados internacionales”, que se basará en el concepto de "integración productiva" y que no es más que "una fuerte interacción de aquellas naciones que poseen complementación comercial mutua”.

\subsubsection{La oposición al ALCA norteamericano}


Como décimo sexto eje de la política exterior, se enuncia que se debe "reforzar y ampliar el Mercosur" oponiéndose a un "Acuerdo de Libre Comercio de las Américas" que podría profundizar "la injusticia y ocasionará el quiebre de nuestras economías”.

Finaliza estos argumentos de política internacional abogando por derribar "las barreras arancelarias y paraarancelarias y la política de subsidios y el proteccionismo de los países centrales" que claramente "oponen trabas al comercio internacional y obstaculizan el crecimiento de los países en desarrollo".

Meses después, en el seno de la Asamblea General de las Naciones Unidas el 21 de septiembre de 2004, se mantiene la determinación de "participar activamente en la acción de las Naciones Unidas" con una propuesta de estar "a favor de la paz, la promoción del desarrollo económico y social sustentable y la erradicación del hambre y la pobreza”.

\subsubsection{La democratización de los organismos internacionales}

A lo mencionado anteriormente, se lo complementa con "una democratización del sistema de decisiones en los organismos internacionales" como el décimo séptimo eje prioritario de la política exterior.

Asimismo, se refuerza el convencimiento de "que no existe alternativa aceptable a la acción multilateral" en el tema del terrorismo y "resulta imprescindible una activa participación y colaboración de toda la comunidad internacional, basada en el respeto del derecho internacional" que se relaciona con "el respeto a los derechos humanos".

"Pero la estabilidad y la seguridad se ven también afectadas por el hambre y la pobreza extrema, por la exclusión social, la ignorancia y el analfabetismo, por la propagación de enfermedades y epidemias y por el daño irreversible al medio ambiente".

$\mathrm{Al}$ año siguiente, el $1^{\circ}$ de marzo de 2005, el presidente Néstor Kirchner inauguró la Asamblea Legislativa y el tema de la deuda continuaba en el centro de la escena. Entonces se tensaba el criterio ya que "esta renegociación tiene plazos otorgados por la ley y debe realizarse en nuestro país conforme a sus normas". Para profundizar este concepto, manifestaba que "nuestra inserción en el mundo no debe estar signada por lo puramente financiero", ya que "para nosotros, inserción en el mundo debe ser comercio exterior e inversión extranjera productiva directa”. Y esta inserción debía ser reforzada "desde el Mercosur", "la negociación con China" y "la relación con países en desarrollo, el acuerdo Sur-Sur", ya que estos "presentan un excepcional potencial de apertura e integración de mercados".

Esto tendría como objetivo "promover el desarrollo de investigaciones tendientes a la elaboración de estrategias regionales que incorporen la temática social 
y de salud en la agenda de integración sudamericana, contribuyendo al progreso social y a la disminución de la pobreza”.

\subsubsection{La relación entre la política exterior y la defensa nacional}

Como resumen, se expone que lo que identifica la política exterior del gobierno es "el multilateralismo, la paz y el respeto a la autodeterminación de los pueblos", lo que junto a la "política de defensa" ubica la "presencia militar en diversas partes del mundo bajo el mandato de las Naciones Unidas". Esta relación constituye el décimo octavo eje de la política internacional del período.

Además, está política "está indisolublemente ligada al país que somos, al país que queremos ser, al proyecto de país que queremos construir" guiada por la "autonomía en las decisiones" para generar "un desarrollo sustentable con inclusión social" que permita "incrementar la generación de empleo, aumentar los niveles de ingresos de los más pobres y darles acceso general a la educación, la salud, la vivienda y lo servicios vitales".

\subsubsection{La oposición al Consenso de Washington}

Como décimo noveno eje caracterizador se enfatizaba que:

"tras la década del 90 en que la Argentina era exhibida como

alumna destacada del Consenso de Washington -pues aplicaba a rajatabla los consejos de apertura indiscriminada y renunciaba a los principales instrumentos para defender su producción-, culminó incendiándose y quedando en el más grande aislamiento internacional del que se tenga memoria”.

Asimismo, para cambiar este patrón de desarrollo e inserción, es necesario "el fortalecimiento, la ampliación y la profundización del Mercosur" y la constitución "de la Comunidad Sudamericana", profundizando "los acuerdos alcanzados con China, India, Pakistán, Vietnam, Marruecos y Corea" que "abren una fase nueva e interesante; además de incrementar el volumen de nuestras exportaciones" y exploran "formas asociativas para la inversión productiva".

En el ámbito de la 60 Asamblea General de las Naciones Unidas el 14 de septiembre de 2005, Néstor Kirchner vuelve a mencionar uno de los pilares de la política exterior que es "poner al desarrollo como objetivo central del comercio internacional”.

Al año siguiente, en la Asamblea Legislativa del $1^{\circ}$ de marzo de 2006, se consolidan los ejes planteados en los discursos anteriores.

En esta ocasión, Néstor Kirchner luego de enumerar una serie de logros relacionados al medio ambiente, destaca el inicio del: 


\section{"Programa Nacional de Normalización Documentaria} Migratoria Patria Grande, a partir de la firma de un convenio con los estados provinciales, cuyo objetivo es regularizar a todos los inmigrantes del Mercosur y países asociados en situación irregular que lo soliciten y que vivan en el país".

Acto seguido, se resumen varios de los ejes centrales de la política exterior: todos los recursos de la política exterior -el "fortalecimiento del derecho internacional", la "promoción de valores asociados a la paz internacional y la democracia", el "respeto de los derechos humanos y a la búsqueda de un sistema de comercio equilibrado que contemple una mejor distribución de los beneficios de la globalización"- se orientan a una verdadera "democratización del sistema de decisiones en los organismos internacionales" y un fuerte "multilateralismo".

Y esta institucionalidad apunta a la "promoción del desarrollo socioeconómico y el combate contra la pobreza" y el respeto del "derecho internacional de los derechos humanos" como una "política de Estado que forma parte de nuestra identidad como nación, razón por la cual constituye uno de los ejes centrales de la política exterior llevada a cabo por nuestra Cancillería".

Néstor Kirchner participa de la $61^{\circ}$ Asamblea General de las Naciones Unidas el 20 de septiembre de 2006 y manifiesta su "apoyo a la jerarquización de los derechos humanos" que llevó a la "creación del Consejo de Derechos Humanos, en cuya gestación la Argentina participó activamente”.

En esta alocución mantiene una alineamiento indirecto y pragmático -por fuera de la retórica tensional in crescendo- con los Estados Unidos, al considerar que

"todos los actos de terrorismo son criminales e injustificables y no acepta ningún argumento que intente justificar tal metodología", pero aclarando que "si para enfrentar a ese terrorismo global se recurre a una violación global de los derechos humanos, el único victorioso en esa lucha será el terrorismo".

\subsubsection{El replanteo de la arquitectura financiera internacional}

En el marco de esta Asamblea y como vigésimo eje constitutivo, se propone una "reforma de la arquitectura financiera internacional, de manera que resulte ser funcional al progreso de las naciones de menores recursos".

Este tema le permitió al gobierno liderar, a nivel internacional, un reclamo de muchos países que finalizó exitosamente en una resolución de la Asamblea General.

$\mathrm{Al}$ año siguiente, al inaugurar la Asamblea Legislativa del $1^{\circ}$ de marzo de 2007, el presidente Kirchner, radicalizó su discurso al sostener que el país se había librado de la "dictadura del Fondo Monetario Internacional manejando los destinos de los 
argentinos". Esto le había permitido ganar "autonomía cancelando la deuda" y propone reformar este organismo internacional "estructuralmente".

En este discurso, apareció una profundización del concepto de autonomía al enfatizar:

"Señores: es hora de que tengamos la mayoría de edad, que tengamos nuestra propia decisión y no tengamos miedo, porque nadie se subordina ideológicamente a nadie. Este país siempre será un país latinoamericanista, independiente, plural y amplio con todos los pueblos de América del Sur".

El presidente Néstor Kirchner dirige su último discurso ante la Asamblea de las Naciones Unidas el 20 de septiembre 2007 manifestando que,

"como cada año de nuestro mandato, concurrimos a esta Asamblea General con el ideal de revitalizar este ámbito de representación global, en la convicción de que ello aportará la vigencia del derecho internacional como instrumento capaz de dirimir conflictos y así poder enfrentar con éxito las amenazas a la paz".

La propuesta para los problemas del mundo es "la multilateralidad", "el respeto de todos los países a las normas y convenciones internacionales" y "el pleno respeto a los derechos humanos".

A su vez, en un mundo violento, "la paz será posible en la medida en que se promueva la igualdad y se luche por erradicar la pobreza, la indigencia y la exclusión”.

\subsection{El Gobierno de Cristina Fernández de Kirchner}

El 10 de diciembre de 2007, Cristina Fernández de Kirchner da su discurso de asunción ante la Asamblea Legislativa y menciona

"los cuatro capítulos fundamentales de este proceso que hemos iniciado el 25 de mayo de 2003 y que tiene en las instituciones, en la sociedad, en un modelo económico de acumulación con matriz diversificada e inclusión social y en nuestra inserción en el mundo, los cuatro ítems fundamentales: las instituciones".

En este discurso fundacional de su gobierno resalta que "este nuevo modelo económico de matriz diversificada, de acumulación con inclusión social que se ha puesto en marcha" es

"la clave para los tiempos que vienen; un modelo que, reconoce en el trabajo, en la producción, en la industria, en la exportación, en el campo, la fuerza motriz que ha permitido que millones de 
argentinos vuelvan a recuperar no solo el trabajo, sino además las esperanzas y las ilusiones de que una vida mejor es posible".

Y destaca el rol del estado "que coloque a la infraestructura económica y social como otro de los ejes de la inversión y del desarrollo de la actividad económica".

En relación con el Mercosur, lo considera como "nuestra Casa la América latina” que es "nuestro espacio al que esperamos que se incorpore a la brevedad Venezuela para cerrar la ecuación energética de América latina, porque alimentos y energía serán la clave de un futuro que ya está aquí en la puerta, que no es tan lejano”.

Al finalizar, enfatiza un eje de la política exterior que es "la reconstrucción del multilateralismo. Un mundo unilateral es un mundo más inseguro, más injusto”.

$\mathrm{Al}$ año siguiente, Cristina Fernández de Kirchner, al dirigirse a la Asamblea Legislativa del $1^{\circ}$ de marzo de 2008, marca como prioridad la integración "en América latina, aquí, en la América del Sur, aquí, en el Mercosur”. Pero este Mercosur debe ampliarse con "la incorporación de la República Bolivariana de Venezuela" con el objetivo de cerrar finalmente la ecuación energética”.

Como en todos discursos, finaliza con el "reclamo permanente que tenemos sobre nuestras islas Malvinas", que ha sido "siempre un fuerte reclamo ante esa vergüenza que significa, en pleno siglo XXI, el enclave colonial en el Atlántico Sur, un acto humanitario: que Inglaterra permita a los deudos, a los familiares de los que murieron y están enterrados en Malvinas ir en avión”.

\subsubsection{Herencia y continuidad de la política exterior}

Al trasladarse al escenario internacional, ante la $63^{\circ}$ Asamblea de las Naciones Unidas del 23 de septiembre de 2008, Cristina Kirchner afirma dos conceptos claves del modelo de inserción internacional que hereda de su esposo. Por un lado, la importancia de "nuestra región, la América del Sur". Por otro, "cómo se reconstruye una multilateralidad a pesar de las diferencias de enfoque y de visión que podemos tener los distintos gobiernos de la región”.

Posteriormente en el discurso ante la Asamblea Legislativa del 1 de Marzo del 2009, Cristina Fernández de Kirchner entra en una etapa de radicalización del discurso le resulta imprescindible para el mantenimiento de su base electoral. En este sentido menciona que llevará a la reunión del G-20 un reclamo basado en que "hay un modelo en crisis que tiene que ver también con una forma de relacionarse en el mundo basado en la subordinación y no en la cooperación".

Esto da como resultado que "se ha quebrado la confianza y muchas sociedades están al borde de su capacidad de endeudamiento", porque uno "de los problemas fundamentales del mundo, es lograr reactivar la demanda global, única manera de reactivar la economía, además también de lograr fuentes de financiamiento”. 
Y elevando la apuesta del diagnóstico, entiende que "estamos ante la crisis de un sistema de ideas que hizo de la especulación, de la subordinación, de un mundo donde unos pocos mandan y el resto obedece”.

Ese mismo año, en su Discurso en la 64a Asamblea General de las Naciones Unidas, en Nueva York el 23 de septiembre de 2009, refuerza el concepto central de la política exterior que es el "multilateralismo" que "va a exigir por parte de todos nosotros acciones y reglas concretas para que todos, absolutamente todos tengamos los mismos parámetros a la hora de juzgar conductas y situaciones institucionales".

La insistencia sobre cambiar la ecuación económica de los actores y sus intereses se manifiesta nuevamente en el Discurso de la Asamblea Legislativa del 1 de Marzo de 2010, que menciona que la Argentina integra el G-20 "junto a los principales países del mundo" y en ese espacio se planteó que "uno de los principales problemas que no era solamente salvar a los bancos, que había que hacerlo para no repetir la crisis del '30, pero que había que sostener la demanda agregada para que hubiera crecimiento".

Cuando expone el discurso argentino en la $65^{\mathrm{a}}$ Asamblea General de las Naciones Unidas, en Nueva York, del 24 de septiembre de 2010, se refuerza el concepto de "la construcción de la paz y la seguridad internacional" y se lo ejemplifica con la "reanudación del diálogo entre el Estado de Israel y la Autoridad de Palestina".

\subsubsection{Virajes conceptuales en el plano regional}

Pequeños cambios se concretan en la política exterior de Cristina Fernández. En este caso, en el discurso del 1 de marzo de 2011 en la Asamblea Legislativa, la presidenta se concentra en resaltar "el compromiso" que tuvimos en "la UNASUR, que este 11 de marzo cobra vigencia porque ya ha sido aprobado por la cantidad de estados necesarios, para que UNASUR sea realmente hoy una institución de la región, y haber tenido la Argentina el honor de tener la primera Secretaría General”. Este tema se convierte en el vigésimo primer eje constitutivo como es la ampliación del espacio regional al consolidar instituciones que complementan el Mercosur.

Al exponer en la Asamblea General de las Naciones Unidas el 21 de septiembre de 2011, hace un nuevo planteo de "la reforma de los organismos multilaterales de crédito, especialmente el Fondo Monetario Internacional, y también de los organismos políticos de esta honorable organización”.

A continuación, ofrece un balance de los 8 años anteriores, al mencionar que "la Argentina ha reestructurado su deuda haciendo una reducción del 160 por ciento que comprendía del PBI, a menos del 30 por ciento. Los índices de pobreza e indigencia se han reducido a un dígito y todavía debemos seguir dando pelea. Tenemos un índice 
de desocupación que es uno de los más bajos de toda la serie y hemos completado el ciclo de crecimiento económico más importante en nuestros 200 años de historia”.

Luego, refuerza uno de los ejes centrales de la política internacional que es "la multilateralidad, algo que hemos defendido consecuentemente siempre, la necesidad de un mundo más plural, más diverso".

A su vez, insiste en "democratizar los organismos políticos como Naciones Unidas y fundamentalmente su Consejo de Seguridad.

Al año siguiente, en la Asamblea Legislativa del 1 de marzo de 2012, el contenido de su discurso se centra en Malvinas, "que se ha convertido en una causa regional, americana y global, y que es necesario abordar con seriedad, con mucha seriedad, que es lo que estamos haciendo". Asimismo, remarca que "el interés de los isleños" no justifica "una militarización de las islas", en tanto "hoy las Malvinas tienen una población total de 2.955 personas, hay 1.000 efectivos, hay más de un soldado cada tres personas".

\subsubsection{Regulando el capital}

En la 67a Asamblea General de las Naciones Unidas, en Nueva York, el 25 de septiembre de 2012, se plantea la crisis económica del mundo que se inició en 2008 y se la relaciona con "la administración financiera de capitales sin ningún tipo de regulación" como "la causante de esto, que ya es una crisis global". Este tema se transforma en el vigésimo segundo eje de la política exterior.

A pesar de esto, "el FMI sigue reclamando políticas de ajuste" que van "en detrimento de nuestras economías y fundamentalmente en detrimento de la inclusión de millones de ciudadanos que solo ahora han podido ser incluidos en el aparato productivo".

Y la resolución de este problema no debe concebirse como "un problema económico, sino que estamos ante un problema político" que intenta mostrar la necesidad de un Estado con capacidades reguladoras sobre el mercado.

Al año siguiente, en el discurso en la Asamblea Legislativa del 1 de marzo de 2013, Fernández de Kirchner fundamenta el Mercosur como "política de Estado iniciada durante el gobierno del presidente Alfonsín y rescatada nuevamente por el presidente Kirchner y el presidente Lula”.

Esta integración se expande a "la Patria Grande, la UNASUR" como forma de reunir apoyos para "la postura de Argentina en Malvinas y repudiando el accionar de los fondos buitre. El mundo que clama por diálogo.

El tema de Malvinas se relaciona en el discurso de las Naciones Unidas el 24 de septiembre de 2013 con el Tratado de no Proliferación Nuclear, al ser "la Argentina 
uno de los países de mayor, sino tal vez el de mayor desarrollo nuclear de América latina”.

Pero este desarrollo nuclear "con fines pacíficos y científicos" tiene un componente comercial, al vender "generadores nucleares a Egipto, a Argelia, a Australia" con "fines medicinales". Esto hace que

"no andamos condenando el uso de la energía nuclear con fines de guerra y al mismo tiempo desplazamos submarinos nucleares como nos pasa -por ejemplo- a los argentinos en nuestra disputa de soberanía sobre nuestras Islas Malvinas, donde el Reino Unido militariza el Atlántico Sur y envía submarinos nucleares”.

En el discurso en la Asamblea Legislativa del $1^{\circ}$ de marzo de 2014, plantea dos temas. El primero, muy controvertido, es el acuerdo con Irán: este acuerdo "fue pensado y ejecutado para destrabar una situación y un hecho que ocurrió en 1994”. El segundo tema, es la cuestión Malvinas. En esta oportunidad, le suma otro componente al económico, que tiene que ver con que el Reino Unido quiere "tener una base militar en el Atlántico Sur".

A diferencia de estos dos temas, en el discurso de la 69a Asamblea General de las Naciones Unidas el 25 de septiembre de 2014, los temas centrales son la deuda externa, el terrorismo internacional, la cuestión Malvinas y la organización de las Naciones Unidas.

$\mathrm{Al}$ año siguiente, en el Discurso en la Asamblea Legislativa del 1 de marzo del 2015, introduce el tema de "los acuerdos con China" y sostiene que "estamos en un mundo totalmente diferente, no al de hace 10 años". En este sentido, "el mundo dentro de 5 años, no dentro de 5 siglos, va a ser diferente. Dentro de 5 años China va a ser el actor económico más importante, si ya no lo es, del mundo”.

El último discurso, en la 70ª Asamblea General de las Naciones Unidas el 28 de septiembre de 2015, quiere dejar en claro su legado en los temas internacionales, al mencionar los siguientes puntos.

Primero, el capitalismo se encuentra en "un proceso de concentración económica inédita en el mundo". Segundo, debe tornarse internacional el tema de la "igualdad de género". Tercero, la especulación financiera es la que gobierna el sistema económico internacional y debemos "volver a inyectar recursos a la economía". Cuarto, el tema del uso pacífico de la energía nuclear debe tener en cuenta que "Argentina integra el selecto club de países productores de energía nuclear, pero que también somos líderes en materia de no proliferación. Por lo tanto, para nosotros la no proliferación nuclear es también una cuestión de Estado”. Quinto, señala la importancia del "Mercosur, de la UNASUR, de la CELAC que tanto peleamos". Sexto, incluye la necesidad de reforzar los “cuerpos multilaterales" del sistema internacional. 


\section{Conclusiones}

De la totalidad de las fuentes documentales discursivas del período kirchnerista interpretadas a través del estado de la discusión de los autores se desprende que el modelo de inserción internacional del Kirchnerismo se fundamentó en su relación con un modelo de crecimiento interno. Este vínculo interdependiente es más sustantivo que en los gobiernos anteriores del periodo histórico democrático.

Asimismo, el patrón de inserción internacional se caracterizó por un realismo discursivo presidencial estado-céntrico distributivo de orientación latinoamericana que generó una ruptura con el periodo anterior de carácter formalista y conservador.

A partir de esta relación entre la dinámica del proceso de desarrollo interno y el diseño de la política internacional, podemos resumir los siguientes ejes centrales como características de la política exterior.

1. Un discurso fundacional para la Argentina que instala un nuevo modelo de paradigma de desarrollo nacional.

2. Una ruptura con el pasado como forma de construir un modelo de acumulación distributivo.

3. La centralidad del estado como pilar del desarrollo interno y como instrumento para la inserción internacional.

4. El regionalismo como mecanismo de construcción de poder frente al resto del mundo hegemónico.

5. La importancia de la resolución de la deuda externa como problema económico estructural.

6. El fortalecimiento del derecho internacional como plataforma de construcción de poder real a través de las instituciones internacionales.

7. Un multilateralismo periférico, entendido como el reconocimiento del país perteneciente al sur global, pero con posibilidades de superar las asimetrías de poder a través de una relación con la mayoría de actores, niveles y temas posibles en el sistema internacional.

8. El reclamo de las Islas Malvinas como un legado permanente e histórico, pero escalando el componente discursivo como un colonialismo del siglo XXI.

9. Una reconfiguración de la relación con los Estados Unidos combinada con aspectos de ruptura en el plano discursivo, pero con el mantenimiento de temas en común en la agenda estratégica.

10. La participación en las misiones de paz siempre con el aval institucional de legitimidad de las Naciones Unidas.

11. La lucha contra el terrorismo internacional como estrategia de poder real en el tema central de la agenda mundial. 
12. La reestructuración del esquema agroexportador articulando la diversificación de las exportaciones con un mayor valor agregado.

13. La enunciación en los foros internacionales de un mundo desigual como estrategia para sostener un modelo de inserción de matriz latinoamericana enfrentando el bloque hegemónico internacional.

14. La incorporación de los derechos humanos en la agenda internacional como reflejo de la coalición interna de gobierno.

15. El cumplimiento con el pago a los organismos internacionales orientado a generar un desarrollo sustentable independiente y con grados elevados de autonomía.

16. La oposición al Alca y una priorización de la integración latinoamericana.

17. La democratización de los organismos y las decisiones internacionales, proponiendo el fortalecimiento de la Asamblea General.

18. La política de defensa como instrumento de la política exterior.

19. La oposición al Consenso de Washington como el responsable de las políticas de ajuste y endeudamiento de los países de América Latina y la Argentina.

20. El replanteo de la arquitectura financiera internacional en el marco de la Asamblea General de las Naciones Unidas.

21. La ampliación del regionalismo latinoamericano y la construcción de la Unasur para institucionalizarlo.

22. La propuesta en el plano internacional de una mayor regulación de los capitales internacionales orientados al desarrollo y desmotivando la especulación financiera.

En síntesis, la política exterior del gobierno de Néstor Kirchner y Cristina Fernández de Kirchner se sustentó en una priorización de los asuntos internos frente a los internacionales en términos funcionales a un modelo nacional distributivo. Esto se instrumentó con una posición de autonomía relativa frente al mundo, con un marcado multilateralismo político y económico, y una confrontación discursiva al status quo del poder mundial y la estructuración de intereses consolidados. Para esto, se le dio una prioridad central al regionalismo como sustento colectivo frente al resto del mundo, lo que se sumó a buscar relaciones con actores desafiantes como aliados prioritarios, tal es el caso de China, entre otros.

\section{Referencias bibliográficas}

Actis, E. (2015). Los condicionamientos domésticos en los diseños de politica exterior: la internacionalización del capital brasileño y su impacto en la politica exterior de Brasil (2003-2013). Implicancias en la relación bilateral con la Argentina (Tesis doctoral). Facultad de Ciencia Política y Relaciones Internacionales de la 
Universidad Nacional de Rosario, Rosario. Recuperado de https://rephip.unr.edu.ar/bitstream/handle/2133/9200/tesis\%20doctoral\% 20actis\%20con\%20caratula.pdf?sequence $=4 \&$ is Allowed $=\mathrm{y}$

Bolinaga, L. (2015). Política china en el Río de la Plata. ¿Asociación Estratégica o Nueva Dependencia? Nueva Sociedad, 259, septiembre-octubre, 69-80. Recuperado de https://nuso.org/articulo/politica-china-en-el-rio-de-laplata/

Busso, A. (2006). La presidencia de Kirchner y los vínculos con Estados Unidos. Más ajustes que rupturas. En A. B. Bologna (Comp.), La politica exterior en el Gobierno de Kirchner (Tomo IV, Volumen II) (pp. 11-127). UNR Editora. Recuperado de http://www.publicacionescerir.com/pdf/Libros/TomoIV_Vol2_Gobierno Kirchner.pdf

Casullo, M. E. (2014/2015). ¿En el nombre del pueblo? Por qué estudiar al populismo hoy. POSTData, 19 (2), octubre de 2014 - marzo de 2015, 277-313. Recuperado de http://www.revistapostdata.com.ar/2014/11/en-elnombre-del-pueblo-por-que-estudiar-al-populismo-hoy-maria-esperanzacasullo/

---- (2019). ¿Por qué funciona el populismo? Siglo XXI Editores.

Colacrai, M. (2010). Argentina-Chile. Las relaciones políticas y el crecimiento de un notable tejido de vínculos a escala nacional y subnacional. En A. B. Bologna (Dir.), La politica exterior del Gobierno de Cristina Fernández: apreciaciones promediando su mandato (Tomo V) (pp. 321-363). UNR Editora. Recuperado de http://www.publicacionescerir.com/pdf/Libros/PEA_TomoV.pdf

---- (2016). Cuando la frontera dialoga: Singularidades de la relación argentinochilena en las últimas décadas [When the border talks: Singularities of the Argentine-Chilean relationship in recent decades]. Estudios Fronterizos, 17 (34), 85-99. Recuperado de http://www.scielo.org.mx/scielo.php?script=sci_abstract\&pid=S0187$69612016000200085 \& \operatorname{lng}=$ es\&nrm=iso

Corigliano, F. (2011). La política exterior del gobierno de Cristina Fernández de Kirchner: una típica política peronista del siglo XXI. Mural Internacional, II (1), junio, 22-27. DOI: https://doi.org/10.12957/rmi.2011.5377

De la Balze, F. A. M. (2010). La política exterior de los gobiernos Kirchner (20032009). Estudios Internacionales, 43 (166), 121-139. Recuperado de https://core.ac.uk/download/pdf/46533717.pdf 
Fernández de Kirchner, C. (10 de diciembre de 2007). Discurso ante la Asamblea Legislativa en ocasión de la toma de posesión del cargo de Presidenta de la Nación. Congreso de la Nación Argentina.

---- (1 de marzo de 2008). Discurso ante la Asamblea Legislativa en ocasión de la inauguración del $126^{\circ}$ período de sesiones ordinarias del Congreso de la Nación. Congreso de la Nación Argentina.

---- (23 de septiembre de 2008). Discurso ante la $63^{\circ}$ Asamblea General de las Naciones Unidas. Organización de las Naciones Unidas.

---- (1 de marzo de 2009). Discurso ante la Asamblea Legislativa en ocasión de la inauguración del 127 periodo de sesiones ordinarias del Congreso de la Nación. Congreso de la Nación Argentina.

---- (23 de septiembre de 2009). Discurso ante la $64^{\circ}$ Asamblea General de las Naciones Unidas. Organización de las Naciones Unidas.

---- (1 de marzo de 2010). Discurso ante la Asamblea Legislativa en ocasión de la inauguración del $128^{\circ}$ periodo de sesiones ordinarias del Congreso de la Nación. Congreso de la Nación Argentina.

---- (24 de septiembre de 2010). Discurso ante la $65^{\circ}$ Asamblea General de las Naciones Unidas. Organización de las Naciones Unidas.

---- (1 de marzo de 2011). Discurso ante la Asamblea Legislativa en ocasión de la inauguración del $129^{\circ}$ periodo de sesiones ordinarias del Congreso de la Nación. Congreso de la Nación Argentina.

---- (21 de septiembre de 2011). Discurso ante la $66^{\circ}$ Asamblea General de las Naciones Unidas. Organización de las Naciones Unidas.

---- (10 de diciembre de 2011). Discurso ante la Asamblea Legislativa en ocasión de la toma de posesión del cargo de Presidenta de la Nación. Congreso de la Nación Argentina.

---- (1 de marzo de 2012). Discurso ante la Asamblea Legislativa en ocasión de la inauguración del $130^{\circ}$ periodo de sesiones ordinarias del Congreso de la Nación. Congreso de la Nación Argentina.

---- (25 de septiembre de 2012). Discurso ante la 67 Asamblea General de las Naciones Unidas. Organización de las Naciones Unidas.

---- (1 de marzo de 2013). Discurso ante la Asamblea Legislativa en ocasión de la inauguración del $131^{\circ}$ periodo de sesiones ordinarias del Congreso de la Nación. Congreso de la Nación Argentina.

- (24 de septiembre de 2013). Discurso ante la $68^{\circ}$ Asamblea General de las Naciones Unidas. Organización de las Naciones Unidas.

---- (1 de marzo de 2014). Discurso ante la Asamblea Legislativa en ocasión de la inauguración del $132^{\circ}$ periodo de sesiones ordinarias del Congreso de la Nación. Congreso de la Nación Argentina. 
- (25 de septiembre de 2014). Discurso ante la $69^{\circ}$ Asamblea General de las Naciones Unidas. Organización de las Naciones Unidas.

---- (1 de marzo de 2015). Discurso ante la Asamblea Legislativa en ocasión de la inauguración del $133^{\circ}$ periodo de sesiones ordinarias del Congreso de la Nación. Congreso de la Nación Argentina.

---- (28 de septiembre de 2015). Discurso ante la $70^{\circ}$ Asamblea General de la Naciones Unidas. Organización de las Naciones Unidas.

Garcen, B., J. (1995) Understanding Argumentation Schemes: An Empirical Research on the Recognition of Type of Argument. En R. Grootendrost, F. van Eemeren, J.A. Blair y Ch. A. Willard, Reconstruction and Application. Proceeding of the Second International Conference on Argumentation, International Centre for the Study of Argumentation, 3, Amsterdam: Sit Sat.

George, A. L. (1969). The "operational code": A neglected approach to the study of political leaders and decisión-making. International Studies Quaterly, 13 (2), junio, 190-222. Recuperado de: https://www.jstor.org/stable/3013944

---- (1991). La decisión presidencial en politica exterior. El uso eficaz de la información y el asesoramiento. Grupo Editor Latinoamericano.

Hermann, M. G. (1980). Explaining Foreign Policy Behavior Using the Personal Characteristics of Political Leaders. International Studies Quarterly, 24 (1), 7 46. Recuperado de https://www.jstor.org/stable/2600126

Kirchner, N. (25 de mayo de 2003). Discurso ante la Asamblea Legislativa en ocasión de la toma de posesión del cargo de presidente de la Nación. Congreso de la Nación Argentina.

(25 de septiembre de 2003). Discurso ante la $58^{\circ}$ Asamblea General de las Naciones Unidas. Organización de las Naciones Unidas.

---- (1 de marzo de 2004). Discurso ante la Asamblea Legislativa en ocasión de la inauguración del $122^{\circ}$ período de sesiones ordinarias del Congreso de la Nación. Congreso de la Nación Argentina.

---- (21 de septiembre de 2004). Discurso ante la $59^{\circ}$ Asamblea General de las Naciones Unidas. Organización de las Naciones Unidas.

---- (1 de marzo de 2005). Discurso ante la Asamblea Legislativa en ocasión de la inauguración del $123^{\circ}$ período de sesiones ordinarias del Congreso de la Nación. Congreso de la Nación Argentina.

---- (14 de septiembre de 2005). Discurso ante la $60^{\circ}$ Asamblea General de las Naciones Unidas. Organización de las Naciones Unidas.

---- (1 de marzo de 2006). Discurso ante la Asamblea Legislativa en ocasión de la inauguración del $124^{\circ}$ período de sesiones ordinarias del Congreso de la Nación. Congreso de la Nación Argentina. 
- (20 de septiembre de 2006). Discurso ante la $61^{\circ}$ Asamblea General de las Naciones Unidas. Organización de las Naciones Unidas.

---- (1 de marzo de 2007). Discurso ante la Asamblea Legislativa en ocasión de la inauguración del $125^{\circ}$ periodo de sesiones ordinarias del Congreso de la Nación. Congreso de la Nación Argentina.

---- (25 de septiembre de 2007). Discurso ante la $62^{\circ}$ Asamblea General de las Naciones Unidas. Organización de las Naciones Unidas.

Lafer, C. (2002). La identidad internacional de Brasil. Fondo de Cultura Económica.

Llenderrozas, E. (2012). La política exterior de los gobiernos kirchneristas. En A. Malamud y M. De Luca (Coords.), La politica en tiempos de los Kirchner (pp. 251-264). Eudeba.

Lorenzini, M. E. (2006). La política exterior durante la administración Kirchner entre mayo de 2003 y diciembre de 2005 ¿Retórica o práctica autonomista? Temas $y$ Debates, 11, 93-113. Recuperado de https://temasydebates.unr.edu.ar/index.php/tyd/article/view/152/0

---- (2007). La estrategia de inserción internacional de la República de Chile en el hemisferio 1990-2004 (Tesis de maestría). Centro de Estudios en Relaciones Internacionales de Rosario, Rosario.

Míguez, M. C. (2016a). La política exterior argentina y su vinculación con los condicionamientos internos en el siglo XXI. Relaciones Internacionales, 89 (2), 125-142.

Recuperado de https://www.revistas.una.ac.cr/index.php/ri/article/view/9067

---- (2016b). La política exterior 2002-2015: nuevos aliados y el dilema de la autonomía. En M. Rapoport (Ed.), Historia oral de la politica exterior argentina (1966-2016) (pp. 85-115). Editorial Octubre.

Miranda R. (2009). Corolario de Brasil: la Argentina sin poder en el nuevo tablero regional. Relaciones Internacionales, 18 (37), mayo-noviembre, 169-186. Recuperado de https://revistas.unlp.edu.ar/RRII-IRI/article/view/1307

---- (2007). La transición inconclusa. Un aspecto del análisis de las relaciones externas de la Argentina entre 2003 y 2007. En N. Consani (Dir.), Anuario 2007 en Relaciones Internacionales (pp. 1-18). Instituto de Relaciones Internacionales de la Universidad Nacional de la Plata.

Nemiña, P. (2011). Estrategias de negociación del FMI y la Argentina durante el período 2003-2004. Temas y Debates, 15 (22), julio-diciembre, 87-113. Recuperado de https://core.ac.uk/download/pdf/61699972.pdf

Rapoport, M. (2008). Argentina y el MERCOSUR: ¿dilema o solución? CICLOS en la historia, la economía y la sociedad, XVII (33-34), 3-18. Recuperado de 
http://bibliotecadigital.econ.uba.ar/download/ciclos/ciclos_v17_n33-

34_01.pdf

Rapoport, M. y Spiguel, C. (2015). Regímenes políticos y política exterior argentina.

En M. Rapoport, (Ed.), Historia oral de la politica exterior argentina, 1930-1966).

Conservadores, peronistas, desarrollistas y radicales (capítulo 3). Editorial Octubre.

Riggirozzi, P. y Tussie, D. (2012). The Rise of Post-Hegemonic Regionalism in Latin America. En P. Riggirozzi y D. Tussie (Eds.), The Rise of Post-Hegemonic Regionalism: The Case of Latin America (capítulo 1). Springer. Recuperado de https://www.researchgate.net/publication/282444747_The_Rise_of_PostHegemonic_Regionalism

Russell, R. (2008). La relación Argentina-Estados Unidos. Pocas expectativas en Buenos Aires y Washington. Foreign Affairs Latinoamérica, 8 (4), 92-08. Recuperado de http://revistafal.com/numeros-anteriores/fal-08-4/

Russell, R. y Tokatlian, J. G. (2011). Percepções argentinas sobre o Brasil: ambivalências e expectativas. En B. Sorj y S. Fausto (Org.), Brasil e América do Sul: Olhares cruzados (pp. 247-273). Plataforma Democrática. Recuperado de

http://www.plataformademocratica.org/Arquivos/Brasil_e_America_do_S ul_Olhares_cruzados.pdf

---- (2015). La política exterior del Kirchnerismo. En C. Gervasoni y E. Peruzzotti (Comp.), ¿Década ganada? Evaluando el legado del Kirchnerismo (pp. 235-269). Debate.

Sanahuja, J. A. (2009). Del "regionalismo abierto" al "regionalismo post-liberal". Crisis y cambio en la integración regional en América Latina y el Caribe. En L. Martínez Alfonso, L. Peña y M. Vázquez (Coords.), Anuario de la Integración de América Latina y el Gran Caribe 2008-2009 (pp. 11-54). Coordinadora Regional de Investigaciones Económicas y Sociales. Recuperado de https://www.researchgate.net/publication/303111093_Del_'regionalismo_ abierto'_al_'regionalismo_post-

liberal'_Crisis_y_cambio_en_la_integracion_regional_en_America_Latina_ y_el_Caribe

Simonoff, A. (2008). La Política Exterior de los Gobiernos Kirchneristas y la Tercera Posición. Revista Intellector, V (9), julio-diciembre, 1-20. Recuperado de http://www.revistaintellector.cenegri.org.br/ed200809/alejandrosimonoff-site.pdf 
---- (2009). Regularidades de la Política Exterior de Néstor Kirchner. CONfines de Relaciones Internacionales y Ciencia Politica, 5(10), agosto-diciembre, 71-86. Recuperado de http://www.scielo.org.mx/pdf/confines/v5n10/v5n10a6.pdf

---- (2012a). La estructura decisoria en materia de política exterior de la primera administración de Cristina Fernández de Kirchner (2007-2011). En VII Jornadas de Sociología de la UNLP. Jornadas llevadas a cabo en la Universidad Nacional de La Plata entre los días 5 y 7 de diciembre de 2012. Recuperado de

http://www.memoria.fahce.unlp.edu.ar/trab_eventos/ev.2269/ev.2269.pdf ---- (2012b). Cinco claves explicativas para la política exterior argentina posterior a la crisis de 2001. En C. Morasso y G. Pereyra Doval (Comps.), Argentina y Brasil: proyecciones internacionales, Cooperación Sur-Sur e integración (pp. 105131). UNR Editora.

(2013). ¿Las segundas partes nunca fueron buenas? Caracterización preliminar del nuevo mandato de Cristina Fernández de Kirchner (12/2011-3/2013). En VI Encuentro del Centro de Reflexión en Politica Internacional (CERPI) - IV Jornadas del CENSUD. Encuentro y jornadas llevados a cabo en la Universidad Nacional de la Plata el día 13 de septiembre de 2013. Recuperado de http://sedici.unlp.edu.ar/handle/10915/42583

(2014). Analizando a Cristina Fernández: interpretaciones sobre la política exterior desde el segundo gobierno kirchnerista (2007-2013). En A. B. Bologna (Comp.), La politica exterior de Cristina Fernández de Kirchner al finalizar su mandato (Tomo VI) (pp. 433-452). UNR Editora.

Torres, M. A. (2010). Las definiciones principales de la política exterior de la administración Kirchner. En $V$ congreso Latinoamericano de Ciencia Politica. Congreso llevado a cabo en la Universidad Argentina de la Empresa y la Universidad Católica Argentina entre los días 28 y 30 de julio de 2010. Recuperado de http://cdsa.aacademica.org/000-036/845.pdf

Zelicovich, J. (2011). El lugar del MERCOSUR en la política exterior argentina durante los gobiernos de Néstor Kirchner y Cristina Fernández de Kirchner. Relaciones Internacionales, 20 (41), 179-195. Recuperado de https://revistas.unlp.edu.ar/RRII-IRI/article/view/1192.

Wise C. \& Quiliconi C. (2007). China's Surge in Latina American Markets: Policy Challenges and Responses. Politics \& Policy, 35 (3), agosto, 410-438. Recuperado de https://www.researchgate.net/publication/227717406_China's_Surge_in_ Latin_American_Markets_Policy_Challenges_and_Responses 